\title{
CARACTERÍSTICAS MINERALÓGICAS E CRISTALOGRÁFICAS DA GIPSITA DO ARARIPE
}

\author{
F. M. C. Oliveira ${ }^{1}$, L. E. P. Borges' ${ }^{1}$, E. B. Melo ${ }^{1}$, M. L. S. C. Barros ${ }^{2}$
}

${ }^{1}$ Departamento de Geologia, ${ }^{2}$ Departamento de Engenharia de Minas - Universidade Federal de Pernambuco felisbela.oliveira@ufpe.br - ester@ufpe.br - evenildodemelo@yahoo.com.br - mlbarros@ufpe.br

Artigo submetido em outubro/2012 e aceito em novembro/2012

\section{RESUMO}

A gipsita é um sulfato de cálcio di-hidratado e tem o seu principal campo de aplicação industrial a partir da sua transformação para gesso. No Araripe, as minas apresentam diferentes tipos de minério que submetidos a processos de calcinação diferenciados produzem gesso de qualidade diferenciada. Foram descritas macroscopicamente amostras dos seguintes minérios: a) tipo "rapadura;" b) tipo "cocadinha; c) tipo "Johnson"; d) tipo "estrelinha"; e) o alabastro; f) a selenita, além da anidrita. Apresentam-se, neste trabalho, os resultados das investigações em amostras de alguns dos tipos de minérios conhecidos, utilizandose a Difração de Raios-X na expectativa de melhor compreendê-los, visto que atualmente são diferenciados por aspectos meramente morfológicos. Foram realizadas análises difratométricas em amostras dos tipos Jonhson, Rapadura/Cocadinha e Estrelinha. A análise desses difratogramas diagnostica um material puro, bem cristalizado, identificando como única impureza a presença, embora em pequena quantidade, de anidrita nos três tipos estudados. Ainda é possível afirmar que o teor de anidrita é maior no tipo estratificado, seguido pelo tipo estrelinha e no tipo mais nobre - gipsita tipo Jonhson -, embora com concentração de anidrita nos seus nódulos de coloração cinza azulado, fora dos quais ocorre o menor teor entre os três tipos estudados.

PALAVRAS-CHAVE: gipsita, minerais, gesso, Araripe, mineralogia.

\section{MINERALOGICAL AND CRYSTALLOGRAPHIC FEATURES OF THE GIPSUM IN ARARIPE}

\section{ABSTRACT}

Gypsum is a calcium sulfate dihydrate and has its principal field of industrial application from its transformation into plaster. In Araripe, mines present different ore types that subjected to distinguished calcination processes produce plaster in a differentiated quality. Samples of the following minerals were described macroscopically: a)"rapadura" type; b) "cocadinha" type; c) "Johnson" type; d) "estrelinha" type; e) the alabaster; f) the selenite, and the anhydrite. This work presents the results of the investigations on samples of some known types of minerals by using the $X$-Ray Diffraction in hope of better understanding them, since nowadays they are merely differentiated by morphological aspects. Diffractometic analyses were performed on samples of types "Johnson", "rapadura"/"cocadinha" and "estrelinha. The analysis of these diffractograms diagnoses a pure material, well crystallized; however, a single impurity was identified. Although it is in a small amount, anhydrite was found in all three analyzed types. Moreover, it is possible to affirm that the content of anhydrite is higher in the stratified type, followed by the "estrelinha" type and by the nobler type - gypsum "Johnson" - which although its concentration of anhydrite in its bluish gray colored nodules, out of them it occurs the lowest content among the three studied groups.

KEY-WORDS: gypsum, minerals, plaster, Araripe, mineralogy. 


\section{CARACTERÍSTICAS MINERALÓGICAS E CRISTALOGRÁFICAS DA GIPSITA DO ARARIPE}

\section{INTRODUÇÃO}

\subsection{A GIPSITA}

A Gipsita é um sulfato de cálcio dihidratado - $\mathrm{CaSO}_{4} 2 \mathrm{H}_{2} \mathrm{O}$ - cuja composição teórica é $46,6 \% \mathrm{SO}_{3}, 32,5 \% \mathrm{CaO}, 20,9 \% \mathrm{H}_{2} \mathrm{O}$. Cristaliza-se no sistema monoclínico, apresenta a classe prismática, biaxial positivo. Apresenta hábito fibroso (segundo \{001\}), prismático, lamelar a tabular (segundo \{010\}), maciço ou granular. A clivagem se dá em 4 direções (perfeita $\{010\}$ e menos perfeita a imperfeita $\{100\}$ e $\{111\}$. A Dureza varia de 1,5 a 3 . A densidade relativa é 2,32, não sendo considerado um mineral de elevado peso específico. A fratura é conchoidal e apresenta brilho vítreo, nacarado e sedoso. As cores são variadas: de branco a cinza, amarelo, vermelho, castanho, podendo até ser incolor. Acontece associada com calcários, folhelhos, margas e argilas. Seu reconhecimento é feito através de suas propriedades diagnósticas: dureza baixa; hábito; solubilidade em ácido clorídrico $(\mathrm{HCl})$ diluído a quente; relevo negativo; baixa birrefringência; forte dispersão inclinada e caráter óptico. Geminação sobre (100), com forma de ponta de flecha, e também sobre (101). (UNESP, 2005)

A gipsita incorpora-se aos depósitos evaporíticos, constituídos por minerais-minérios dos grupos dos cloretos e sulfatos, de $\mathrm{Ca}-\mathrm{Mg}-\mathrm{K}$, formados por evaporação intensiva de águas salinas em ambientes restritos, geralmente de pouca profundidade e sob climas secos.

Os termos "gipsita", "gipso" e "gesso" são usados freqüentemente como sinônimos. Os termos gipsita e gipso podem ser usados como sinônimos denominando o mineral em estado natural, enquanto gesso indica o produto industrial calcinado a $160-180^{\circ} \mathrm{C}$, hemi-hidratado, mineralogicamente conhecido como bassanita $\left(\mathrm{CaSO}_{4} \cdot 1 / 2 \mathrm{H}_{2} \mathrm{O}\right)$.

O gesso caracteriza-se pela sua forte reação exotérmica com água, razão de sua aplicação ortopédica. Dada à sua hidrofilia controlada, exerce marcante redução da umidade interna de ambientes, otimizando o funcionamento de aparelhos de ar condicionado. Durante séculos, este produto foi empregado de maneira limitada, principalmente para fins ornamentais, sem alcançar maiores aplicações, devido ao seu tempo de pega considerado pequeno (25 a 30 minutos). Nos Estados Unidos, sua utilização na construção civil começou em 1835, mas só se desenvolveu por volta de 1885, com a descoberta de um método comercial para retardar o tempo de pega.

A mais antiga utilização de gipsita é registrada na forma de alabastro, em esculturas e ornamentações egípcias que datam de cerca de 3.000 anos a. C., enquanto os romanos empregaram o gesso no acabamento de construções, tempos depois. No início do século XVIII, a gipsita começou a ser utilizada na Europa como corretivo de solos.

\subsection{IMPORTÂNCIA ECONÔMICA}

As reservas mundiais de gipsita $\left(\mathrm{CaSO}_{4} .2 \mathrm{H}_{2} \mathrm{O}\right)$ correspondem a 2.360 milhões de toneladas e são da ordem de 25 vezes o consumo mundial, que se encontra atualmente em torno de 97 milhões de toneladas por ano. Os principais produtores são Estados Unidos, Canadá, China, França, Irã, Japão, Tailândia, México e Espanha. No território brasileiro os principais depósitos ocorrem associados às bacias sedimentares: Amazônica, Parnaíba, 
Potiguar, Araripe e Recôncavo. Do total das reservas brasileiras, 96\% localizam-se nos Estados da Bahia (43\%), do Pará (35\%) e de Pernambuco (18\%), vindo em seguida os Estados do Maranhão (2,7\%), Tocantins (0,6\%), Ceará $(0,3 \%)$, Piauí $(0,2 \%)$ e Amazonas $(0,1 \%)$. (BALANÇO MINERAL BRASILEIRO, DNPM, 2001).

Do ponto de vista econômico, os principais depósitos estão localizados na Bacia Sedimentar do Araripe (Aptiano-Albiano), sob a forma de dois horizontes estratigráficos, dos quais o superior é sempre mais potente, sobretudo em Pernambuco, onde apenas este tem sido explotado. No Ceará estes dois horizontes são menos potentes, porém a explotação se estende a ambos. Estes dois horizontes constituem o Membro Ipubi da Formação Santana, de Idade Cretácea (BEURLEN, 1971, PONTE \& APPI, 1990).

O Estado de Pernambuco responde por $92,8 \%$ da produção nacional tendo 24 das 30 minas em atividade no País. $O$ aproveitamento destas reservas, nos municípios de Araripina, Bodocó, Exu, Ipubi, Ouricuri e Trindade, gerou um conjunto de atividades empresariais com forte reflexo na economia local, constituindo um "cluster" bastante dinâmico e que recebeu a denominação de "Pólo Gesseiro do Araripe". (BALANÇO MINERAL BRASILEIRO, DNPM, 2001).

Existem ocorrências de gipsita no estado do Ceará, registradas no Cariri, Missão Velha e Crato; também no Rio Grande do Norte, em Dix-Sept Rosado e no Piauí, nos municípios de Serra Vermelha, Simões e Jaicós. A Bahia, que detém $43 \%$ das reservas brasileiras, em Camamu, tem a vantagem de se situar cerca de $1.000 \mathrm{~km}$ mais próxima da região sudeste (principal centro de consumo), apresenta como óbice uma grande espessura do capeamento (30 a 60 m) estando o seu aproveitamento projetado para implantação de lavra subterrânea. O aproveitamento das reservas do Pará tem como fatores impeditivos a grande distância dos centros consumidores e deficiências de infraestrutura. As jazidas do Araripe, em Pernambuco, porém, apresentam capeamento não muito espesso (da ordem de 5,00 metros) e, consequentemente, o que favorece a explotação a céu aberto. A relação estéril/minério é pequena (1:4 ou 1:5) o que torna a retirada do minério bastante viável do ponto de vista econômico. Algumas minas podem exibir esta relação da ordem de 1:2, sendo o minério de melhor qualidade, seu valor comercial permite a viabilização dos custos de extração. Existem outros registros de ocorrências nos Estados de Sergipe, Rio de Janeiro, Acre e Rondônia, entretanto sem informações a respeito de suas reservas, formalmente reconhecidas pelo DNPM.

O minério gipsífero do Pólo Gesseiro do Araripe classifica-se como de excelente qualidade industrial, devido a uma consistente concentração de sulfatos, da ordem de 95\%, onde as impurezas de origem terrígena se apresentam em quantidades desprezíveis, raras vezes ultrapassando a $0,5 \%$ do minério. Embora a gipsita seja predominante, também se fazem presentes quantidades subordinadas de anidrita, em geral de 4 a $7 \%$ mas podendo, às vezes, chegar até $14 \%$ (MENOR, 1995).

\subsection{VARIEDADES MINERALÓGICAS DA GIPSITA}

As variedades mais conhecidas de gipsita são: (1) Espato Acetinado, com aspecto fibroso e brilho sedoso; (2) Alabastro, variedade finamente granulada de aspecto maciço geralmente colorida muito utilizada em esculturas e (3) Selenita, variedade placosa, incolor e translúcida (KLEIN \& DUTROW, 2012), utilizada para produção de acessórios para investigações sob microscopia óptica, sobremodo de luz polarizada. 
No Araripe, as variedades de gipsita são conhecidas como (Borges, et al., 2002): (1) cocadinha (Figura 1), gipsita estratificada com raros filmes de argila verde; (2) rapadura, variedade estratificada que apresenta filmes milimétricos de argila verde; (3) a variedade estrelinha que apresenta cristais radiados em forma de estrela; (4) a gipsita conhecida como Johnson (Figura 2), variedade mais pura, com coloração variando de branco a creme e que caracteriza-se por apresentar uma estrutura com "nódulos" e "estrelas"; (5) o alabastro de aspecto fibroso (Figura 3), que apresenta problemas na calcinação devido ao seu caráter fibroso que promove uma anisotropia que desdobra crepitação e má qualidade ao gesso; (6) a selenita em forma de placas (Figura 4), além da anidrita. Há ainda um material que ocorre formando uma mistura de alabastro e argila, conhecido na região como boró, não raro como capeamento nas jazidas e minas.

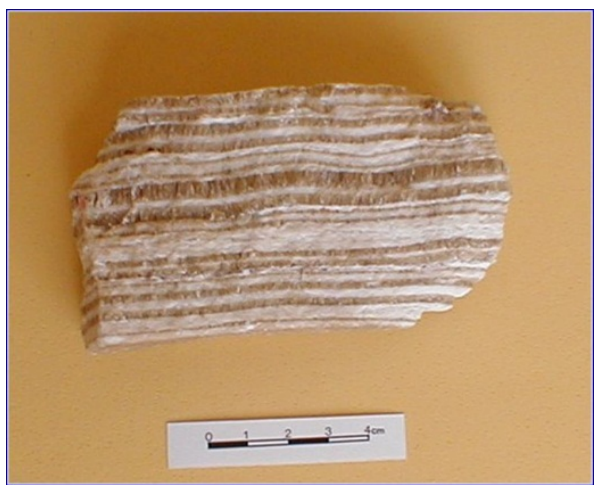

Figura 1 - Cocadinha: gipsita estratificada com raros filmes de argila verde.

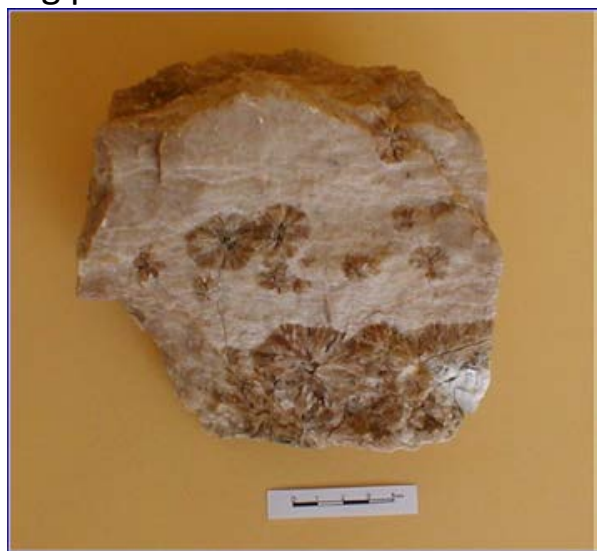

Figura 2 - A gipsita conhecida como Johnson.

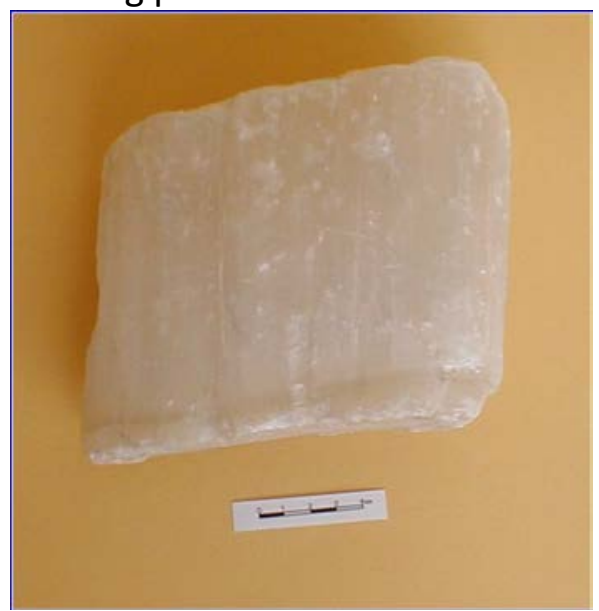


Figura 3 - O alabastro de aspecto fibroso.

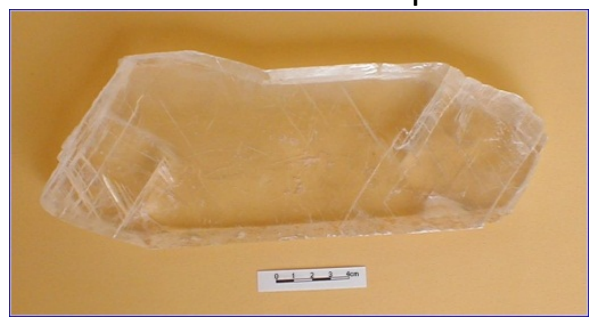

Figura 4 - A selenita em forma de placas.

A partir da gipsita são produzidos o gesso alfa e o gesso beta, com processos de fabricação e aplicações bem diferentes. No momento do desmonte da bancada, já se pode fazer a classificação da gipsita, segundo sua destinação, em:

1) Tipo $A \rightarrow$ para fabricação do gesso alfa $(\alpha)$, odontológico, ortopédico ou cerâmico.

2) Tipo B $\rightarrow$ para fabricação do gesso beta $(\beta)$, para revestimento, cerâmica ou fundição.

3) Tipo $\mathbf{C} \rightarrow$ para refugo, ou para uso como corretivo de solo, na forma de gipsita, com partículas de tamanho entre 0 a $5 \mathrm{~mm}$.

Essa classificação ao mineral-minério, sua associação com impurezas e textura é extensiva aos tipos de minérios, os quais, conforme as observações mais frequentes nas bancadas de exploração atual, distribuem-se da base ao topo conforme descrito abaixo, acrescentando-se o seu potencial de produção dos principais tipos de gesso, ou mesmo aplicações in natura:

- Johnson, que é a pedra branca, mais pura e de maior dureza. Normalmente usada como Tipo A. Neste tipo ocorre a presença de selenita, isto é, cristais bem formados e transparentes, sugerindo tratar-se de cristalização tardia em cavidades com polpa salina residual.

- Estrelinha que é a presença de cavidades com cristalização radial, com cor marrom, caracterizando também cristalização tardia, mas com impurezas argilosas na polpa salina. Usada também como Tipo A.

- Cocadinha, estratificada em camadas mais finas, apresentando cor mais clara, alto teor de alabastro e a menor dureza de todas. Usada como Tipo B.

- Rapadura, estratificada em camadas mais espessas, com dureza intermediária, algum teor de alabastro e cor mais escura. Pode ser usada como Tipo B.

- Boró, material de baixa qualidade, onde a gipsita se encontra misturada com alto teor de argila. Normalmente é usada como matéria prima para corretivo de solos, Tipo C.

No que se refere à contaminação, se a bancada de exploração contiver fraturas preenchidas com boró, o material obtido será recolhido como Tipo $C$, mas se a camada mais fraturada já tiver sido removida, ficando só a face suja, será classificado como Tipo B. Geralmente o tipo conhecido como boró constitui capeamento dos demais tipos de ocorrência.

Há ainda impurezas que precisam ser controladas, tais como:

- Pirita, responsável pela presença de manchas escuras na rocha. Seu teor é tolerável até $1 \%$.

- Anidrita, material inerte que forma nódulos duros: só é tolerável na fabricação de gesso beta para revestimento, controlando-se o seu teor de acordo com o tempo de pega desejado. Ela também pode se formar durante a calcinação da gipsita, se a temperatura ultrapassar determinados limites. A desidratação total da gipsita ocorre em temperaturas acima de $180^{\circ} \mathrm{C}$ 
e resulta nas diferentes formas de anidrita $\left(\mathrm{CaSO}_{4}\right)$. Entre $180^{\circ} \mathrm{C}$ e $250^{\circ} \mathrm{C}$ forma-se a anidrita III, um produto solúvel, instável e ávido por água, podendo absorver umidade atmosférica e passar à forma de hemidrato. Essa propriedade torna a anidrita III um produto com características apropriadas para uso como acelerador de tempo de pega. Na faixa de temperatura entre $300^{\circ} \mathrm{C}$ e $700{ }^{\circ} \mathrm{C}$ obtém-se a anidrita II, um produto insolúvel, de natureza mineralógica semelhante à anidrita natural. A partir dos $900^{\circ} \mathrm{C}$ ocorre a dissociação do sulfato de cálcio com formação do CaO livre (CALVO, 2003).

A seguir listam-se algumas considerações sobre os gessos alfa e beta e suas aplicações: a) Já na seleção do material (minério), a obtenção do gesso alfa se diferencia da do gesso beta, pelo grau de pureza do minério usado.

b) Os processos de fabricação são bastante diferenciados. Enquanto o gesso beta é obtido por calcinação simples, o gesso alfa exige a utilização do sistema de autoclave, seja usando desidratação em meio aquoso, seguida de centrifugação e moagem, seja fazendo o cozimento da gipsita ao vapor d'água sob pressão, seguido de moagem.

c) Observação ao microscópio mostra a diferenciação entre os dois em termos de cristalinidade, de modo que, enquanto o gesso beta tem cristalização completamente irregular, o gesso alfa apresenta cristais uniformes. Normalmente eles são prismas retos, de base hexagonal, cuja altura mede aproximadamente duas vezes o diâmetro do círculo circunscrito à base. Essa cristalinidade se expressa na difratometria através da melhor definição da intensidade dos picos e respectivo posicionamento.

d) Como primeira conseqüência, o gesso alfa oferece alta trabalhabilidade e produz superfícies com acabamento muito superior.

e) Como segunda conseqüência, o gesso alfa alcança resistência à compressão entre 15 e 24 $\mathrm{MPa}$, enquanto o gesso beta fica no intervalo de 1,5 a 2,0 MPa.

f) No preparo da pasta, enquanto o gesso alfa usa 30\% de água, o gesso beta exige $70 \%$.

Para o gesso beta, as aplicações estão no campo da construção civil:

- Fundição - fabricação de elementos pré-moldados como placas para forro, elementos decorativos como sancas e pedestais, blocos divisórios e placas acartonadas ("acartonados"). Esses últimos são produzidos quase que exclusivamente para exportação, sendo utilizados tanto para forros como para divisórias e revestimento.

- Gesso para revestimento manual, com um tempo de pega maior.

- Gesso para revestimento projetado, com pega rápida.

- Argamassas para assentamento.

- Cola de gesso, tanto para alvenaria de blocos, como para fixação de elementos decorativos e acartonados, quando usados em revestimento.

Para o gesso alfa, as principais aplicações são:

- Ortopédicas, nas imobilizações em geral.

- Odontológicas, em restaurações e na moldagem de blocos e elementos ortodônticos.

- Em moldes para peças cerâmicas.

- Em moldes para jóias.

- Na fabricação de argamassas para contrapisos autonivelantes.

A gipsita quando aquecida sofre sucessivas perdas de água de cristalização. Se a taxa de aquecimento for próxima a $10^{\circ} \mathrm{C} / \mathrm{min}$, apresenta duas transformações endotérmicas entre 100 e $200^{\circ} \mathrm{C}$ (na primeira perde $75 \%$ da sua água de cristalização transformando-se no hemidrato, e na segunda perde os $25 \%$ restantes de água de cristalização,transformando-se 
em anidrita). Entre 200 e $1200^{\circ} \mathrm{C}$, só se registra uma exoterma entre 380 e $450^{\circ} \mathrm{C}$ (transformação polimórfica), entretanto muitas amostras de minérios de gipsita apresentam efeitos térmicos acima de $450^{\circ} \mathrm{C}$, causados pela presença de impurezas, tais como argilominerais e carbonatos (TODOR, 1976).

\section{MATERIAIS E MÉTODOS}

As amostras utilizadas procedem de minerações pertencentes ao Pólo Gesseiro do Araripe, em Pernambuco. Foram coletados os minérios conhecidos regionalmente como: Jonhson, Rapadura, Cocadinha e Estrelinha.

Os procedimentos analíticos incluíram difractometria de Raios- $X$.

As análises difratométricas foram realizadas no Laboratório de Difração de Raios -X do Departamento de Física da UFPE utilizando-se o DRX - D 5000, marca Siemens, radiação de CuK $\alpha$, com passo de $0.02^{\circ} / \mathrm{seg}$, no intervalo $2 \theta$ de 8 a $50^{\circ}$ em amostras dos tipos Jonhson, Rapadura/Cocadinha e Estrelinha.

\section{RESULTADOS E DISCUSSÕES}

É perceptível a importância da separação entre os tipos de minério de gipsita (cocadinha, rapadura, Jonhson, etc.) para as suas aplicações e mais oportuno ainda, porque constitui terminologia regional integrada ao conhecimento de todos envolvidos localmente com a atividade.

Outro aspecto interessante é perceberem-se os controles de posicionamento dos diversos tipos enfocados neste trabalho, os quais, em cada jazida, ocupam papel prenunciador de perspectivas e operacionalidade. Assim, os mais abrangentes e importantes são os tipos estratificados - cocadinha e rapadura, pois são usados na construção civil. Quando apresentam contaminação com argila, isso resulta em dificuldades à produção e qualidade do gesso.

O tipo boró, sempre capeador do conjunto de evaporitos, tem na argila, que se associa ao alabastro, o indício da potencialidade e preservação natural dos pacotes subpostos: enquanto argila esverdeada aponta para preservação dos evaporitos, argilas avermelhadas são indicadoras de processos de retrabalhamento e dissolução do evaporito, um dia sotoposto, mas solubilizado.

Finalmente o tipo "Johnson", o mais nobre, localizado mais inferiormente no pacote evaporítico, foi provavelmente o último a se cristalizar graças à proteção dos níveis argilosos associados aos tipos já citados. Outrossim, a sua disposição sob formas cujo topo é frequentemente curvilíneo, gerando corpo de forma maciça, sugere associação com estruturas atectônicas tipo antiforme de compensação, decorrentes de deslizamentos.

A presença de cristais transparentes no interior de cavidades sugere reforço à tardicristalização supracitada.

A análise dos difratogramas dos três tipos de gipsita (cocadinha-estratificada (Figura 5), estrelinha (Figura 6) e Johnson (Figura7)) diagnostica um material puro, bem cristalizado, identificando como única impureza a presença, embora pequena, de anidrita nos três tipos estudados. Essa afirmação se baseia no diagnóstico do seu pico de maior intensidade $(d=3,489)$, que não está sobreposto a nenhum dos picos apresentados pela gipsita. Ainda é 
possível afirmar que o teor de anidrita é maior no tipo estratificado, seguido pelo tipo estrelinha e no tipo mais nobre - gipsita tipo Johnson -, embora com concentração de anidrita nos seus nódulos de coloração cinza azulado, fora deles ocorre o menor teor entre os três tipos estudados.

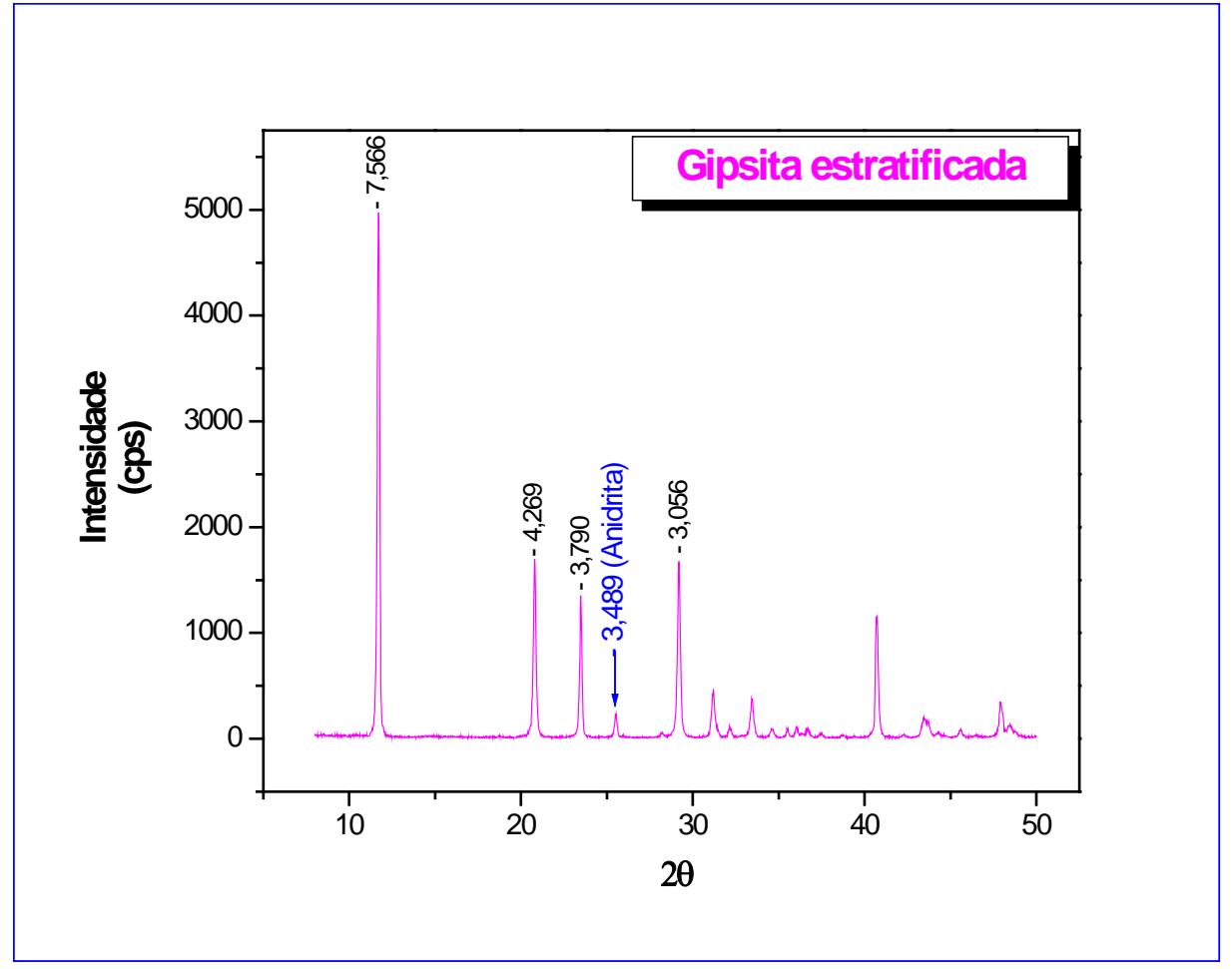

Figura 5- Análise difractométrica da gipsita estratificada, em azul pico da anidrita.

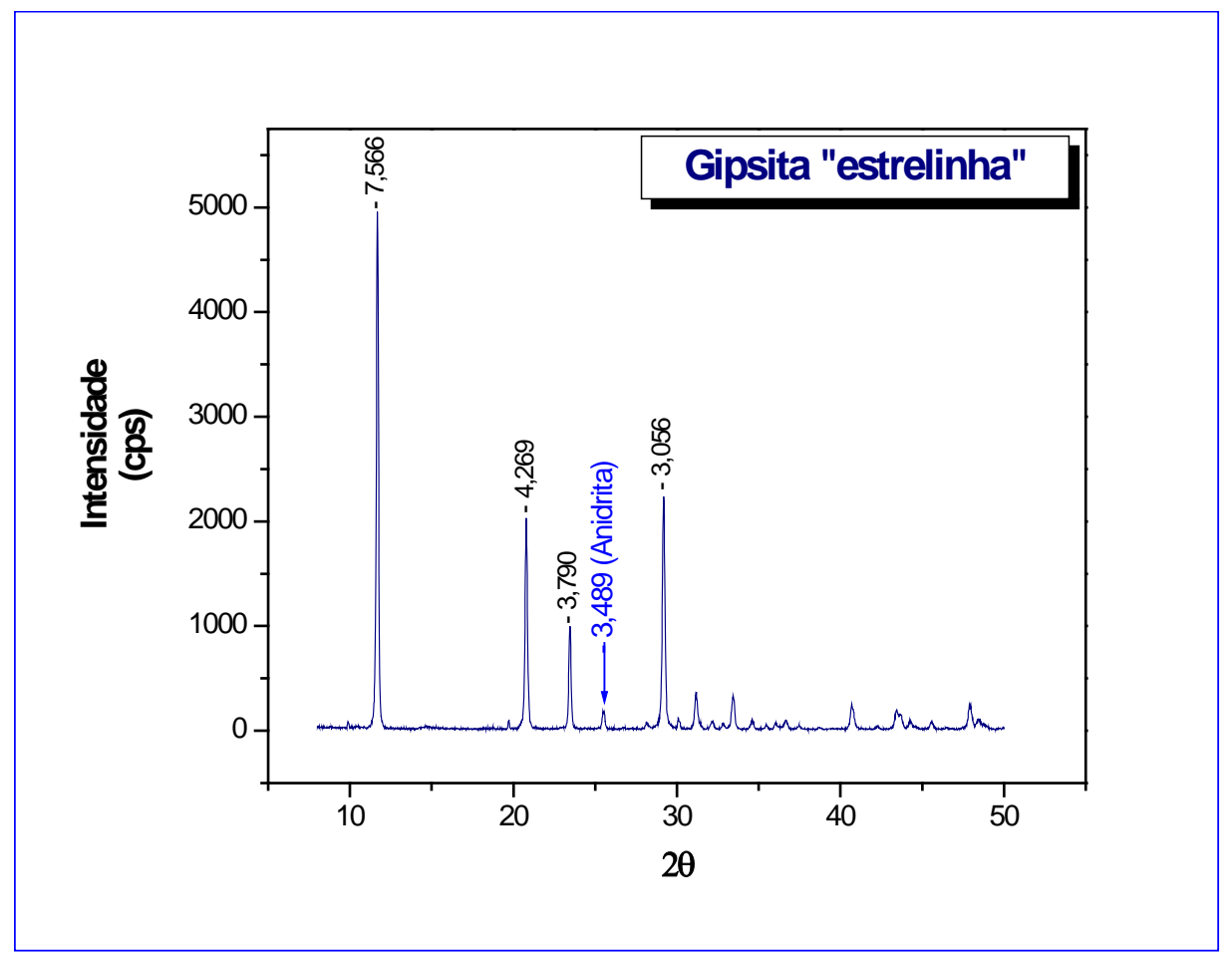

Figura 6 - Análise difractométrica da gipsita estratificada, em azul claro pico da anidrita. 


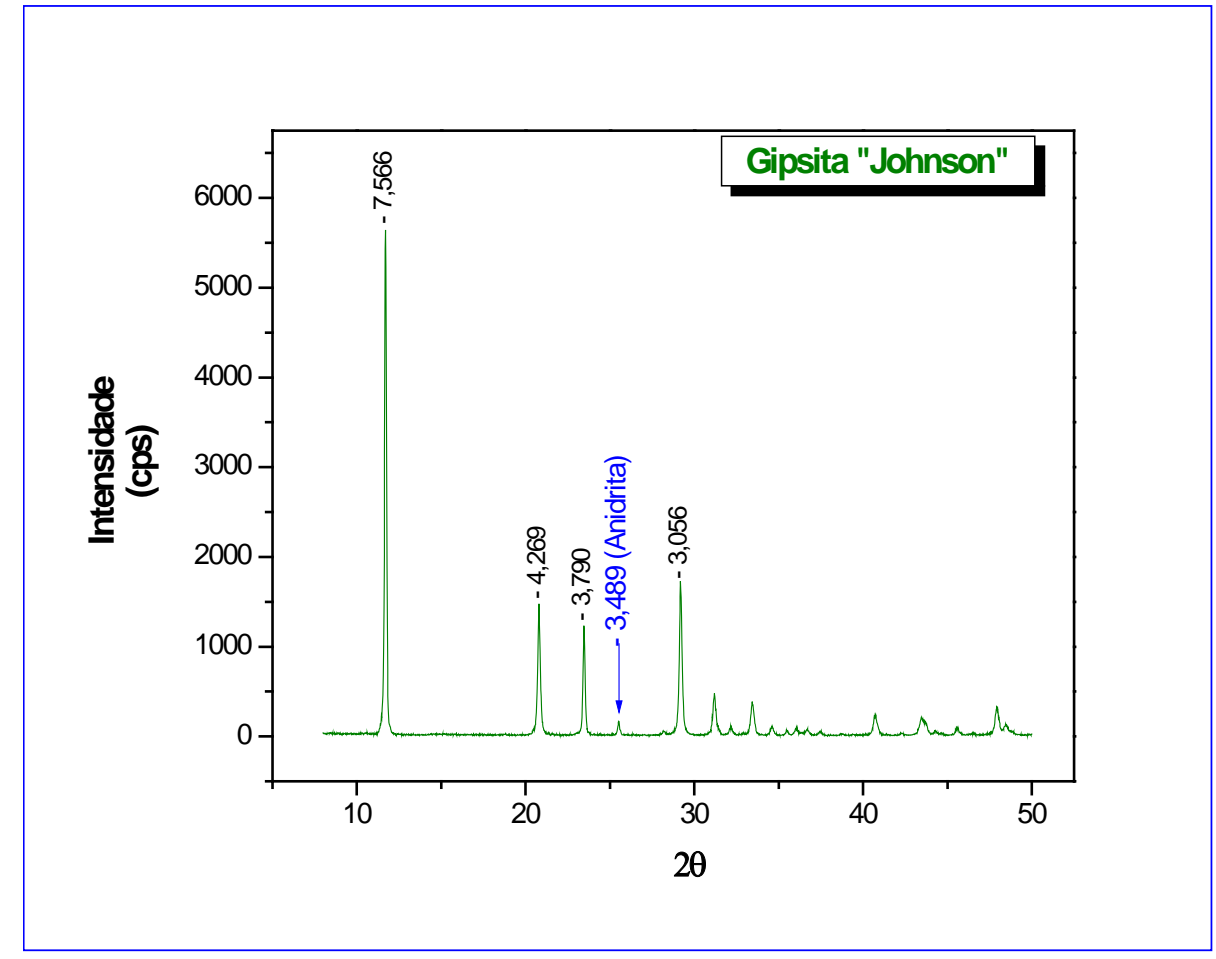

Figura 7 - Análise difractométrica da gipsita estratificada, em azul pico da anidrita.

Observou-se também diferenças estruturais entre o gesso $\alpha$ (Figura 8) e o gesso $\beta$ (Figura 9) usando ainda análise difractométrica, conforme pode ser observado nos difratogramas a seguir, onde os padrões difractométricos são distintos e são confrontados na Figura 10.

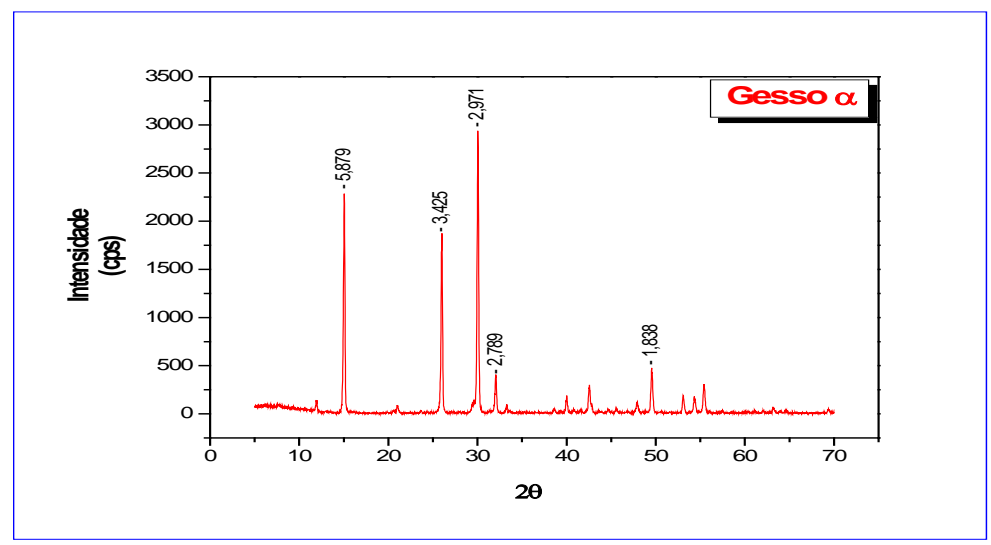

Figura 8 - Padrão difractométrico do gesso $\alpha$ 


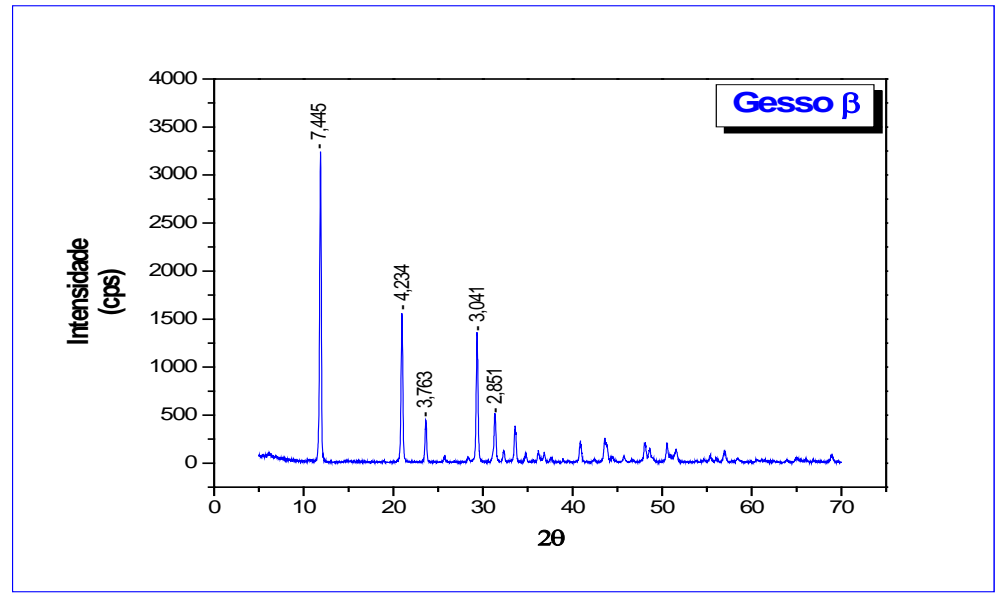

Figura 9 - Padrão difractométrico do gesso $\beta$

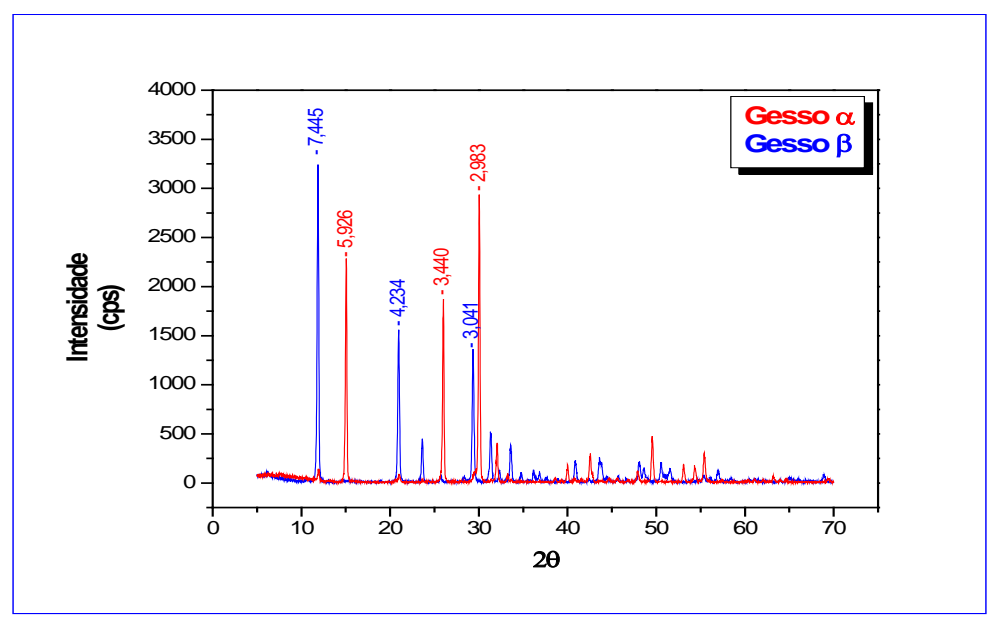

Figura 10 - Comparação entre os padrões difractométricos do gesso $\alpha$ (vermelho) e o gesso $\beta$ (azul).

Os padrões do gesso beta são próximos daquele da gipsita, qualquer que seja o tipo estudado deste mineral. Entretanto o padrão do gesso alfa é bastante diferente daquele das gipsitas estudadas. A microestrutura da gipsita, em seu estado natural, é constituída de cristais geminados de sistema monoclínico (DANA, 1969). A célula unitária da gipsita é cúbica de face centrada (CFC), composta por 4 íons de $\mathrm{SO}_{4}{ }^{2-}, 4$ íons de $\mathrm{Ca}^{2+}$ e 2 moléculas de $\mathrm{H}_{2} \mathrm{O}$. A estrutura do sulfato de cálcio dihidratado é essencialmente composta por duas camadas de grupos $\mathrm{SO}_{4}{ }^{2-}$. Estas estão unidas entre si fortemente por íons de cálcio formando um estrato. Estes estratos, estão por sua vez, devidamente unidos por uma camada de moléculas de água, cada uma das quais une um íon de cálcio com um oxigênio do seu mesmo estrato e com um outro oxigênio do estrato vizinho (ALTABA apud SOUSA, 2009). O aquecimento da gipsita, no processo de fabricação do gesso, modifica sua microestrutura, como se observa na análise dos difractogramas. Sousa, 2009, indica que a temperatura de beneficiamento influencia o sistema cristalino da gipsita, pois a mudança de fase decorridas das reações de desidratação faz com que esta também mude sua estrutura cristalina. Sousa, 2009, mostra ainda os sistemas cristalinos da gipsita como pode ser observado na Tabela 1 (DANA, 1969).

Tabela 1 Sistemas cristalinos da gipsita de acordo com seu beneficiamento (DANA apud SOUSA, 2009) 


\begin{tabular}{l|l|l}
\hline FÓRMULA & SISTEMA CRISTALINO & MINERAL \\
\hline $\mathrm{CaSO}_{4} 2 \mathrm{H}_{2} \mathrm{O}$ & Monoclínico & Gipsita \\
\hline $\mathrm{CaSO}_{4} 0,5 \mathrm{H}_{2} \mathrm{O}$ & Hexagonal & Hemidrato \\
\hline $\mathrm{CaSO}_{4} \varepsilon \mathrm{H}_{2} \mathrm{O}$ & Hexagonal & Anidrita III \\
\hline $\mathrm{CaSO}_{4}$ & Ortorrômbica & Anidrita II \\
\hline $\mathrm{CaSO}_{4}$ & Cúbica & Anidrita I \\
\hline
\end{tabular}

No caso específico dos hemidratos, sua microestrutura se distingue pelo grau de cristalização e pelo tamanho de cristais (TAYLOR, 1998). Os hemidratos alfa e beta possuem a mesma estrutura cristalina, entretanto, sua morfologia (tamanho e superfície do cristal) difere devido ao método de produção (SOUSA, 2009).

As diferenças entre os padrões difractométricos se traduzem, na prática, por valores diferenciados de resistência dos tipos alfa e beta. $O$ hemidrato alfa passa por uma modificação na morfologia do gesso resultando em um produto mais homogêneo, com maior resistência mecânica e menor consistência, após a adição de água. Esta última característica possibilita a trabalhabilidade da mistura com uma menor relação água/gesso. Pelo fato de a resistência mecânica do gesso ser inversamente proporcional à relação água/gesso e, conseqüentemente, à porosidade, as pastas produzidas com o hemidrato alfa são mais resistentes que as produzidas com o beta (NOLHIER apud ANTUNES, 1999). O gesso beta por consumir mais água durante o processo de hidratação apresenta menores resistências mecânicas.

\section{CONCLUSÕES}

Todos os minérios da gipsita são qualitativamente diferenciados pela natureza textural e também quanto ao mínimo conteúdo de anidrita, dado que coloca a busca de aplicações para a anidrita cuja presença associada à gipsita aponta para diferenciações de aplicações. $A$ análise dos difratogramas diagnostica um material puro, bem cristalizado, identificando como única impureza a presença, embora em pequena quantidade, de anidrita nos três tipos estudados. Ainda é possível afirmar que o teor de anidrita é maior no tipo estratificado, seguido pelo tipo estrelinha e no tipo mais nobre - gipsita tipo Jonhson -, embora com concentração de anidrita nos seus nódulos de coloração cinza azulado, fora dos quais ocorre o menor teor entre os três tipos estudados. A análise dos difractogramas indica que o aquecimento durante o processo de fabricação do gesso modifica a estrutura cristalina do mineral original. Os gessos alfa e beta, produzidos a partir de processos industriais diferentes, apresentam mesma estrutura cristalina, mas morfologias variadas. Esta diferenciação se traduz por resistências mecânicas com valores diversos sendo maior para o gesso alfa.

\section{REFERÊNCIAS BIBLIOGRÁFICAS}


BALANÇO MINERAL BRASILEIRO, 2001, DNPM;

BALTAR, C.A.M.; BASTOS, F. F. - Avaliação dos processos de calcinação para produção de gesso Beta. In XLIII CONGRESSO BRASILEIRO DE QUÍMICA, A03-059, 2003, Ouro Preto. Anais do Congresso. Minas Gerais: 22 a 26 de setembro de 2003, 329p.

BALTAR, C.A.M.; BASTOS, F. F., Luz, A. B., Rochas e Minerais Industriais, Gipsita, CETEM, Rio de Janeiro, 2005, pag. 449-470;

BEURLEN, K. 1971. As condições ecológicas e faciológicas da Formação Santana na Chapada do Araripe (Nordeste do Brasil). Anais da Academia brasileira de Ciências, 43(suplemento): 411-415.

BORGES, et al., ANAIS do XLI Congresso Brasileiro de Geologia, João pessoa, PB, 2002, pág 184;

CALVO, J.P. Yeso. In.: Curso Internacional de Técnico Especialista en Rocas y Minerales Industriales. Madrid, 29 de setembro a 03 de outubro, 2003, 16 p.

DANA, J.D. Manual de Mineralogia. v.1. Rio de Janeiro: Ao Livro Técnico, 1969. 642 p

DANA, HURLBUT. Manual de Mineralogia. Editora da Universidade de São Paulo, 1976.

KLEIN \& DUTROW, Manual de Ciência dos Minerais. 23 Ed. Porto Alegre: Bookman, 2012.

Menor E.A., Amaral A.J.R. e Souza V.C. (1995). Projeto Gipsita: Relatório Preliminar. Recife, DNMM, Projeto Gipsita, Relatório Técnico. Etapa I, 42 pp. (inéd.).

PONTE, F.C. \& APPI, C.J. 1990. Proposta de Revisão da Coluna Litoestratigráfica da Bacia do Araripe. In: CONGRESSO BRASILEIRO DE GEOLOGIA. Anais 1, p 211-226.

Relatório Final do Projeto "Otimização das Atividades Extrativas da Gipsita no Araripe com ênfase na Preservação Ambiental, Recife, fevereiro/2006, UFPE;

SOUSA, D. A. P., Condicionamento do gesso proveniente da neutralização do licor de lixiviação da casca de arroz para utilização na construção civil, Escola de Engenharia de Lorena, USP, 2009, 59p.

TODOR, D. N., Thermal Analysis of Minerals. Abacus Press, Romania, 1976, 256 p.

UNESP, Enciclopédia Multimídia Minerais, Departamento de Petrologia e Metalogenia, 2005. 